\section{Kidney Blood Pressure Research}

\title{
Assessment of Renal Pathological Changes in Lupus Nephritis Using Diffusion Weighted Imaging: A Multiple Correspondence Analysis
}

\author{
Zhenfeng Zheng ${ }^{a}$ Tiekun Yan ${ }^{\mathrm{a}}$ Junya Jia ${ }^{\mathrm{a}}$ Dong Lia Li Weia Wenya Shanga \\ Huilan Shib
}

aDepartment of Nephrology, Tianjin Medical University General Hospital, Tianjin, bepartment of Radiology, Tianjin Medical University General Hospital, Tianjin, China

\section{Key Words}

Lupus nephritis - Diffusion weighted imaging - Renal pathology • Multiple correspondence analysis $\cdot$ Magnetic resonance imaging

\begin{abstract}
Background/Aims: Renal pathological changes affect the motion of water molecules, which can be detected using diffusion-weighted imaging (DWI). The current study was performed to explore the correlation between renal tissue pathological injuries and DWI iconographical parameters in lupus nephritis (LN). Methods: Twenty adult patients with LN and 11 healthy volunteers were recruited. Patients with LN received renal biopsies and renal DWI-MRI inspections. The renal biopsy tissues were characterized based on the ISN/RPS 2003 classification. The volunteers, who were of comparable gender and age, only underwent renal DWI-MRI inspection. Four DWI parameters, namely, apparent diffusion coefficient (ADC), pure diffusion coefficient $\left(D_{t}\right)$, pseudo-diffusion coefficient $\left(D_{p}\right)$, and perfusion fraction $\left(f_{p}\right)$, were calculated using monoexponential and biexponential functions, respectively. Data from different renal areas and pathological pattern groups were compared. Multiple correspondence analysis (MCA) was performed to explore the correlation between each DWI index and multiple pathological features. Results: $A D C, D_{t^{\prime}}$ and $f_{p}$ values were lower in the $L N$ group compared to the controls $(P<0.001)$ regardless of the renal area in the cortex and medulla. $D_{p}$ values were higher in the LN group $(P=0.004)$. A difference in mean DWI parameters was found between three $L N$ subgroups and the healthy volunteers, with the exception of the $D_{p}$ index in the renal cortex. MCA showed that serious proliferative pathological injuries and lower ADC and $D_{t}$ values were located in the same quadrant. The MCA plots of $D_{p}$ and $f_{p}$ provided similar results. Higher $D_{p}$ and $f_{p}$ values were located in the MCA plot quadrant with more serious
\end{abstract}




\section{Kidney Blood Pressure Research}

Kidney Blood Press Res 2018;43:847-859

\begin{tabular}{l|l}
\hline DOI: $10.1159 / 000490333$ & (c) 2018 The Author(s). Published by S. Karger AG, Basel
\end{tabular}

Published online: 5 June, 2018

www.karger.com/kb

Zheng et al.: DWI MRI in Lupus Nephritis

proliferative pathological changes. Conclusion: DWI is a noninvasive technique that may be used to detect renal pathophysiological changes. Renal cell proliferation and intestinal fibrosis may impact the movement of water in certain microenvironments. Enhanced perfusion may be a compensatory mechanism that is associated with renal pathological injuries.

(C) 2018 The Author(s)

Published by S. Karger AG, Basel

\section{Introduction}

Systemic lupus erythematous (SLE) is a multisystem autoimmune disease with diverse clinical manifestations, and multiple environmental and/or genetic pathogeneses [1]. The renal system is commonly involved in patients with SLE and it is also a significant cause of morbidity and mortality [2]. Lupus nephritis (LN) is one of the most common forms of secondary glomerulonephritis in China. An epidemiological investigation by Pan et al., reported that $\mathrm{LN}$ was found in approximately $2.37 \%$ to $25 \%$ of all biopsy-confirmed renal diseases and in approximately $27.2 \%$ to $80.65 \%$ of renal disease biopsies performed for secondary causes of glomerular disease [3]. Clinically, renal biopsy is a useful assessment method in patients with LN. However, due to the increased risk of complications, such as bleeding, its use is limited. Therefore, the identification of a noninvasive, real-time method of assessing renal structure and function is needed.

Functional MRI techniques, such as diffusion-weighted imaging (DWI), have the potential to assess intra-renal pathophysiological changes and abnormal kidney function. For example, previous studies have shown a close correlation between renal tissue microstructure and the apparent diffusion coefficient (ADC), which is calculated from DWI signals with monoexponential functions. Furthermore, considering the microenvironment intravoxel incoherent motion (IVIM) effect, and calculating other parameters via biexponential function, allows for the assessment of pure molecular diffusion separate from microcirculation (capillary diffusion). The IVIM model provides multiple significant DWIMRI indices, including true-diffusivity $\left(D_{t}\right)$, pseudo-diffusivity $\left(D_{p}\right)$, and perfusion fraction $\left(f_{p}\right)$ [4-6]. Reduced ADC values have been detected in patients with renal dysfunction and attributed to either reduced water reabsorption or renal fibrosis, which restricts water diffusion [7, 8]. Thus, IVIM analysis has the potential to assess different aspects of renal physiology, such as vascular perfusion, tubular flow, and water reabsorption [4]. Clinically, radiologists and nephrologists appreciate the utility of the DWI-MRI technique in assessing renal physiological or pathological changes. Previous studies have shown that the DWI technique is a sensitive method for detecting renal function in patients with chronic kidney disease [9], evaluating renal allografts function [10], assessing the severity of renal pathology, and guiding therapy for patients with CKD [11]. To the best of our knowledge, only two studies focused on the use of DWI-MRI in LN have been published. One study, published by Rapacchi et al. in 2015, evaluated $10 \mathrm{LN}$ patients and 10 matched healthy volunteers. In this study, the ADC values determined by DWI-MRI were not significantly different between the LN and control groups [12]. Another study by Li et al. (2014), which recruited 65 LN patients and 16 healthy volunteers, found a negative correlation between the mean ADC values and renal pathology chronicity indices [13]. Due to the limitations of using monoexponential function algorithmic ADC values, these two studies failed to uncover detailed pathological information.

The primary purpose of this study was to investigate the correlation between DWIMRI iconographical features and renal pathological characteristics. We used a biexponential formula algorithm in addition to other DWI parameters to investigate multiple pathological injuries that impact the motion of water molecules in the renal tissue microenvironment of patients with LN. 


\section{Kidney Blood Pressure Research}

\section{Materials and Methods}

\section{Study Protocol}

Participants. This single-center observational study was approved by the Ethics Committee of Tianjin Medical University General Hospital, and informed consent was obtained from all of the participants. This study was conducted in accordance with the Declaration of Helsinki. Twenty patients and 11 healthy volunteers were recruited from January 2015 to June 2017. All of the patients fulfilled the 2012 International Collaborating Clinics classification criteria and all of them had undergone renal biopsy [14]. Disease activity was assessed using the SLEDAI (SLE Disease Activity Index) [15], and serum creatinine values were used to calculate current estimated glomerular filtration rate (eGFR) using the Chronic Kidney Disease Epidemiology Collaboration (CKD-EPI) formula [16]. Healthy volunteers were recruited from different divisions of the hospital; no evidence of kidney disease or renal injury was found among these participants. Twenty recruited patients with LN received underwent renal biopsy and DWI-MRI inspection. Eleven healthy volunteers of comparable gender and age only underwent DWI-MRI inspection. To eliminate the effects of medication on results, all of the patients and healthy volunteers were not allowed to use angiotensin converting enzyme inhibitors (ACEIs), angiotensin receptor blockers (ARB), calcium channel blockers (CCB), diuretics, or vasodilators for at least two weeks, as these agents may impact renal blood flow and tubular liquid transportation.

Renal Histopathology. Renal biopsy specimens were fixed in 4.5\% buffered formaldehyde for analysis via light microscopy. Consecutive serial 2-um sections were used for histological staining. Stains used included hematoxylin and eosin, periodic acid-Schiff, silver methenamine, and Masson's trichrome. The renal histopathological data from 20 patients with renal biopsy-confirmed LN were diagnosed by two experienced pathologists according to the ISN/RPS 2003 classification [17]. The pathologists classified and scored the biopsies separately and they were blinded to the patient data and the scores of the other observers. Patients with less than 10 glomeruli in their renal biopsies were excluded. For this study, cases of III $+\mathrm{V}$ were classified as class III and cases of IV+V were classified as class IV. Pathological parameters, such as activity indices and chronicity indices, were approximated by renal pathologists using a modified, previously reported system involving semi-quantitative scoring of specific biopsy features [18].

Magnetic Resonance Imaging Techniques. Magnetic resonance imaging was performed using a 3.0-T Imager (GE Discovery 750 3.0T, General Electric, USA). The scanner had a maximum gradient strength of $50 \mathrm{mT} / \mathrm{m}$ and a slew rate of $200 \mathrm{mT} / \mathrm{m} / \mathrm{sec}$. A Torsopa eight-channel body coil was used. Images were acquired for morphologic evaluation using a $\mathrm{T}_{1}$-weighted fat-suppressed sequence. Images were acquired with a $\mathrm{T}_{1}$ INPHASE+FAT sequence. The field of view (FOV) was $380 \times 380 \mathrm{~mm}$, the section thickness was $7.0 \mathrm{~mm}$, the section width was $1.0 \mathrm{~mm}$, and repetition time (TR)/echo time (TE) was 4286/62.5. Multi b-value DWI-MRI was performed using single-shot echo planar imaging (EPI). Duplicate $\mathrm{T}_{1}$ WI scans were performed at baseline. Images were acquired with $10 \mathrm{~b}$-values $(0,50,100,150,200,250,300,500,800$, and $\left.100 \mathrm{~s} / \mathrm{mm}^{2}\right)$ to sample both the IVIM pseudo-diffusion decay $\left(\mathrm{b}<200 \mathrm{~s} / \mathrm{mm}^{2}\right)$ and the molecular diffusion decay $\left(b>200 \mathrm{~s} / \mathrm{mm}^{2}\right)$. Parameters of DWI are including 8 section number and 8 minutes in each scan time.

Image Analysis. DWI parameter maps, including $\mathrm{ADC}, \mathrm{D}_{\mathrm{t}^{\prime}} \mathrm{D}_{\mathrm{p}}$ and $\mathrm{f}_{\mathrm{p}}$ were constructed on an ADW 4.5 Workstation using the Functool program. Four renal coronal index planes were selected from bilateral kidneys in each participant, so we acquired four groups of DWI images (ADC, $\mathrm{D}_{\mathrm{t}^{\prime}} \mathrm{D}_{\mathrm{p}}$, and $\mathrm{f}_{\mathrm{p}}$ ), with each group including four images (two images of the left kidney and two images of the right kidney). In each coronal DWI parameter plane, the region of interest (ROI) were manually defined in the cortex and medulla. DWI parameter values of each voxel of the selected ROI were obtained by MATLAB 7.10 (MathWorks Inc., Natick, MA, USA). Patient DWI parameter values were calculated using the arithmetic mean of the ROIs in four DWI parameter planes. 


\section{Kidney Blood Pressure Research}

The ADC value was calculated using mono-exponential function. The relationship between signal variation and $\mathrm{b}$ factors was expressed using the following equation:

$$
S_{b} / S_{0}=e^{-b A D C}
$$

The IVIM model considers the diffusivity (D) of the tissue and signal attenuation due to flowing spins. In the kidney, the signal from the flowing spins depends upon the capillary or tubular geometry and the flow velocity. The relationship between the signal variation and $b$ factors was expressed using the following equation:

$$
S_{b} / S_{0}=\left(1-f_{p}\right) e^{-b D_{t}}+f_{p} e^{-b D_{p}}
$$

where $b$ represents the strength of the diffusion gradient, $S_{0}$ the signal intensity without a diffusion gradient, $S_{b}$ is the signal intensity at a given $b$ value, $f_{p}$ is the fraction of diffusion linked to microcirculation, $D_{t}$ is the tissue diffusivity representing pure molecular diffusion, and $\mathrm{D}_{\mathrm{p}}$ is the diffusion parameter representing blood or tubular flow.

\section{Statistical Analyses}

Multivariant Analysis. To compare the difference in the DWI parameters between groups, we used the multivariate analysis of variance (MANOVA) model. MANOVA provides an omnibus test of statistical significance. If this test was statistically significant for the key independent variable, then post hoc comparisons were run to identify which group was statistically different. There are four MANOVA output statistics (Wilk's Lambda, Lawley-Hotelling trace, Pillai's trace, and Roy's largest root) that may be used to judge whether differences between groups exist.

\section{Multiple Correspondence Analysis.} To analyse the relationship between DWI parameters and renal pathological parameters, multiple correspondence analysis (MCA) was applied. MCA is a descriptive/exploratory technique designed to analyze simple two-way and multi-way tables containing measures of correspondence between the rows and columns. The object of MCA is to visualize the relationship of categorical parameters in a graphical manner. Correspondence analysis was used to explore the relationship between variables by comparison with distance in multiple dimension space. In general, the first two dimensions can usually explain the majority variation. We used two dimensions to visualize the correlation of the variables. Detailed, categorized information on DWI indices and pathological parameters are illustrated in Table 1.
Table 1. Value assignment of clinical and pathological

\begin{tabular}{|c|c|c|}
\hline Indexes description & Scale category & Value assignment \\
\hline \multirow[t]{4}{*}{ Glomerular cell proliferation } & None & 1 \\
\hline & Less than $25 \%$ & 2 \\
\hline & $25 \%$ to $50 \%$ & 3 \\
\hline & Greater than $50 \%$ & 4 \\
\hline \multirow[t]{4}{*}{ Leucocyte exudation } & None & 1 \\
\hline & Mild & 2 \\
\hline & Moderate & 3 \\
\hline & Extensive & 4 \\
\hline \multirow[t]{4}{*}{ Karyorrhexis and fibrinoid necrosis } & None & 1 \\
\hline & Less than $25 \%$ & 2 \\
\hline & $25 \%$ to $50 \%$ & 3 \\
\hline & Greater than $50 \%$ & 4 \\
\hline \multirow[t]{4}{*}{ Cellular crescents } & None & 1 \\
\hline & Less than $25 \%$ & 2 \\
\hline & $25 \%$ to $50 \%$ & 3 \\
\hline & Greater than $50 \%$ & 4 \\
\hline \multirow[t]{4}{*}{ Hyaline deposits } & None & 1 \\
\hline & Mild & 2 \\
\hline & Moderate & 3 \\
\hline & Extensive & 4 \\
\hline \multirow[t]{4}{*}{ Interstitial inflammation } & None & 1 \\
\hline & Mild & 2 \\
\hline & Moderate & 3 \\
\hline & Extensive & 4 \\
\hline \multirow[t]{4}{*}{ Glomerular sclerosis } & None & 1 \\
\hline & Less than $25 \%$ & 2 \\
\hline & $25 \%$ to $50 \%$ & 3 \\
\hline & Greater than $50 \%$ & 4 \\
\hline \multirow[t]{4}{*}{ Fibrous crescents } & None & 1 \\
\hline & Less than $25 \%$ & 2 \\
\hline & $25 \%$ to $50 \%$ & 3 \\
\hline & Greater than $50 \%$ & 4 \\
\hline \multirow[t]{4}{*}{ Tubular atrophy } & None & 1 \\
\hline & Mild & 2 \\
\hline & Moderate & 3 \\
\hline & Extensive & 4 \\
\hline \multirow[t]{4}{*}{ Interstitial fibrosis } & None & 1 \\
\hline & Mild & 2 \\
\hline & Moderate & 3 \\
\hline & Extensive & 4 \\
\hline \multirow[t]{2}{*}{ Thicken basement membranes } & No & 1 \\
\hline & Yes & 2 \\
\hline \multirow[t]{4}{*}{$\mathrm{ADC}$ value } & Less than Q1 & 1 \\
\hline & $\mathrm{Q} 1 \sim \mathrm{Q} 2$ & 2 \\
\hline & Q2 Q3 & 3 \\
\hline & Greater than Q3 & 4 \\
\hline \multirow[t]{4}{*}{$D_{t}$ value } & Less than Q1 & 1 \\
\hline & $\mathrm{Q} 1 \sim \mathrm{Q} 2$ & 2 \\
\hline & Q2 Q3 & 3 \\
\hline & Greater than Q3 & 4 \\
\hline \multirow[t]{4}{*}{$D_{p}$ value } & Less than Q1 & 1 \\
\hline & $\mathrm{Q} 1 \sim \mathrm{Q} 2$ & 2 \\
\hline & $\mathrm{Q} 2 \sim \mathrm{Q} 3$ & 3 \\
\hline & Greater than Q3 & 4 \\
\hline \multirow[t]{4}{*}{$f_{p}$ value } & Less than Q1 & 1 \\
\hline & Q1 Q2 & 2 \\
\hline & $\mathrm{Q} 2 \sim \mathrm{Q} 3$ & 3 \\
\hline & Greater than Q3 & 4 \\
\hline
\end{tabular}
indices in lupus nephritis 


\section{Kidney Blood Pressure Research}

Kidney Blood Press Res 2018;43:847-859
\begin{tabular}{l|l}
\hline DOI: $10.1159 / 000490333$ & $\begin{array}{l}\text { C } 2018 \text { The Author(s). Published by S. Karger AG, Basel } \\
\text { www.karger.com/kbr }\end{array}$ \\
Published online: 5 June, 2018 &
\end{tabular}

Zheng et al.: DWI MRI in Lupus Nephritis

All of the analyses were carried out using IBM $^{\circledR}$ SPSS $^{\circledR}$ Statistics software (version 22.0 IBM Corporation; Armonk, NY, USA). Data in the text and table are shown as mean \pm SD. Statistical significance was determined at $\mathrm{P}<0.05$.

\section{Results}

\section{Participant Demographic Information}

There were 20 patients in the LN group who were included in the study and underwent DWI-MRI. The average age of the patients was $34.30 \pm 14.31$ years (ranging from 16-62 years). The mean urine protein was $3.71 \pm 2.81 \mathrm{~g} / 24 \mathrm{~h}$ (ranging from $0.34-9.47 \mathrm{~g} / 24 \mathrm{~h}$ ) and the mean eGFR was $100.60 \pm 25.45 \mathrm{ml} / \mathrm{min} / 1.73 \mathrm{~m}^{2}$ (ranging from $39-138 \mathrm{ml} / \mathrm{min} / 1.73$ $\mathrm{m}^{2}$ ). In the LN group, the mean systolic blood pressure (SBP) and diastolic blood pressure (DBP) were $140.00 \pm 14.86 \mathrm{mmHg}$ and $83.05 \pm 8.08 \mathrm{mmHg}$, respectively. All 20 of the patients underwent a renal biopsy. According to the 2003 ISN/RPS classification system for $\mathrm{LN}$, renal pathological patterns were listed as: III-(A/C) pattern (2 cases), III-(A/C) +V pattern ( 3 cases), IV-G(A/C) pattern (3 cases), IV-S(A/C) pattern (1 case), IV-S(A) pattern (1 case), IV-G(A/C) +V pattern ( 5 cases), IV-S(A/C) +V pattern ( 1 case), and V pattern ( 4 cases). Eleven individuals were recruited for the healthy volunteer group and they underwent DWIMRI. The average age of the healthy volunteers was $33.73 \pm 13.59$ years (ranging from 1656 years). The mean eGFR of the healthy volunteers was $117.00 \pm 13.19 \mathrm{ml} / \mathrm{min} / 1.73 \mathrm{~m}^{2}$ (ranging from $99-141 \mathrm{ml} / \mathrm{min} / 1.73 \mathrm{~m}^{2}$ ). The mean SBP and DBP in the healthy volunteers were $132.18 \pm 8.10 \mathrm{mmHg}$ and $81.73 \pm 6.81 \mathrm{mmHg}$, respectively. No statistically significant difference in age or eGFR was found between the LN group and the healthy volunteers.

\section{Comparison of Renal DWI-MRI Values between LN Patients and Healthy Volunteers}

The mean $A D C, D_{t^{\prime}}$ and $f_{p}$ values were lower in the $L N$ patients than in the healthy volunteers $(P<0.001$ for all of the parameters) regardless of the renal area in both the cortex and medulla. However, the opposite results were found for $\mathrm{D}_{\mathrm{p}}(\mathrm{P}=0.004)$. Details are provided in Table 2 and Fig. 1.

In the renal cortex area, differences in mean DWI parameters were found between the three LN subgroups and the healthy volunteers group, except for the mean $\mathrm{D}_{\text {p }}$ index. Details are provided in Table 3 and Fig. 2. Similar results were also found in the renal medulla area; details are provided in Table 4 and Fig. 3.

\section{Multiple Correspondence Analysis of DWI-MRI Parameters and Pathological Indices}

We explored the complex interrelationships between the pathological indices and DWI-MRI parameters. In the MCA figure between ADC and renal pathological indices, the lower ADC values and several graded pathological characteristics were located in the lower right quadrant. These pathological characteristics included glomerular sclerosis, cellular crescents, glomerular cell proliferation, and interstitial fibrosis; details are provided in Fig. 4. These renal pathological injures may decrease the capacity of molecular diffusion in renal tissues. Similar results were also found in the MCA figure between $\mathrm{D}_{\mathrm{t}}$ and renal pathological indices; details are provided in Fig. 5.

Table 2. Comparison of DWI functions between groups with lupus nephritis and healthy volunteers. Note: ADC: appearance diffusion coefficient; $D_{t}$ : true diffusion coefficient; $D_{p}$ : pseudo-diffusion coefficient; and $\mathrm{f}_{\mathrm{p}}$ : perfusion fraction. Data are shown as mean \pm SD

\begin{tabular}{|c|c|c|c|c|c|c|}
\hline \multirow[b]{2}{*}{ DWI functions } & \multicolumn{2}{|c|}{ Renal cortex } & \multirow[b]{2}{*}{$P$ value } & \multicolumn{2}{|c|}{ Renal medulla } & \multirow[b]{2}{*}{$P$ value } \\
\hline & Lupus nephritis $(N=20)$ & Healthy volunteers $(\mathrm{N}=11)$ & & $\begin{array}{l}\text { Lupus nephritis ( } \mathrm{N}= \\
20)\end{array}$ & Healthy volunteers $(\mathrm{N}=11)$ & \\
\hline ADC & $2.284 \pm 0.184$ & $2.393 \pm 0.085$ & $<0.001$ & $2.258 \pm 0.174$ & $2.358 \pm 0.067$ & $<0.001$ \\
\hline$D_{t}$ & $1.677 \pm 0.314$ & $1.802 \pm 0.285$ & $<0.001$ & $1.597 \pm 0.348$ & $1.734 \pm 0.272$ & $<0.001$ \\
\hline$D_{p}$ & $22.391 \pm 1.979$ & $22.003 \pm 2.033$ & 0.004 & $23.079 \pm 1.333$ & $22.528 \pm 1.633$ & 0.004 \\
\hline$f_{p}$ & $22.343 \pm 2.033$ & $23.949 \pm 0.321$ & $<0.001$ & $22.368 \pm 1.581$ & $23.530 \pm 0.735$ & $<0.001$ \\
\hline
\end{tabular}




\section{Kidney \\ Blood Pressure \\ Research}

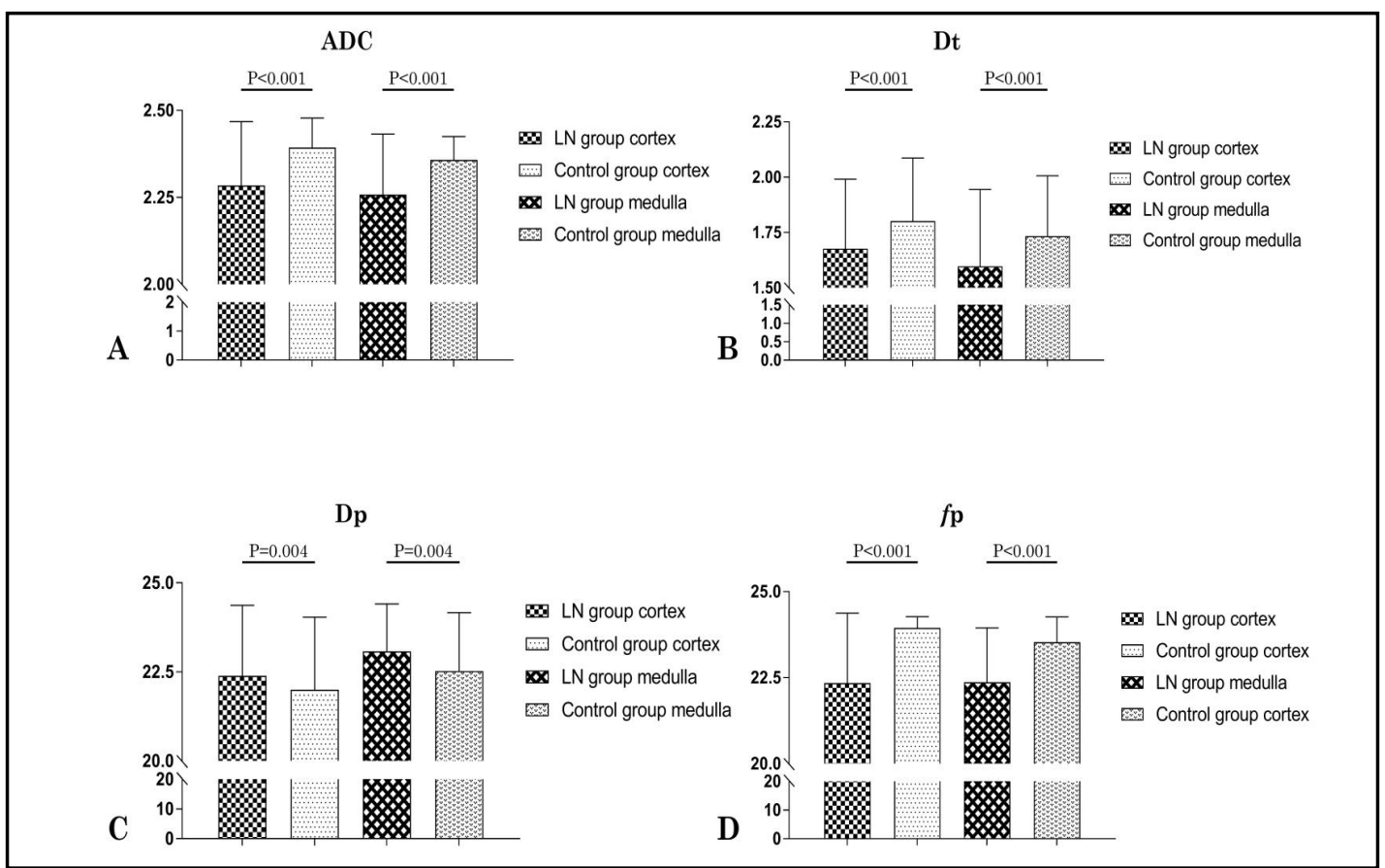

Fig. 1. Comparison of DWI indices between lupus nephritis patients and healthy volunteers.

Table 3. Comparison of DWI functions in the renal cortex between lupus nephritis subgroups and healthy volunteers. Note: ADC: appearance diffusion coefficient; $\mathrm{D}_{\mathrm{t}}$ : true diffusion coefficient; $\mathrm{D}_{\mathrm{p}}$ : pseudo-diffusion coefficient; and $\mathrm{f}_{\mathrm{p}}$ : perfusion fraction. Data are shown as mean $\pm \mathrm{SD}$

\begin{tabular}{|c|c|c|c|c|c|}
\hline DWI functions & Lupus nephritis III class $(\mathrm{N}=5$ ) & Lupus nephritis IV class $(\mathrm{N}=11)$ & Lupus nephritis V class $(\mathrm{N}=4)$ & Healthy volunteers $(\mathrm{N}=11)$ & $P$ value \\
\hline $\mathrm{ADC}$ & $2.217 \pm 0.219$ & $2.303 \pm 0.122$ & $2.358 \pm 0.120$ & $2.393 \pm 0.085$ & $<0.001$ \\
\hline $\mathrm{D}_{\mathrm{t}}$ & $1.548 \pm 0.304$ & $1.688 \pm 0.302$ & $1.781 \pm 0.305$ & $1.802 \pm 0.285$ & $<0.001$ \\
\hline $\mathrm{D}_{\mathrm{p}}$ & $22.768 \pm 1.326$ & $22.535 \pm 2.132$ & $21.703 \pm 2.317$ & $22.003 \pm 2.033$ & 0.059 \\
\hline $\mathrm{f}_{\mathrm{p}}$ & $22.167 \pm 2.191$ & $22.286 \pm 1.745$ & $23.188 \pm 1.062$ & $23.949 \pm 0.321$ & $<0.001$ \\
\hline
\end{tabular}

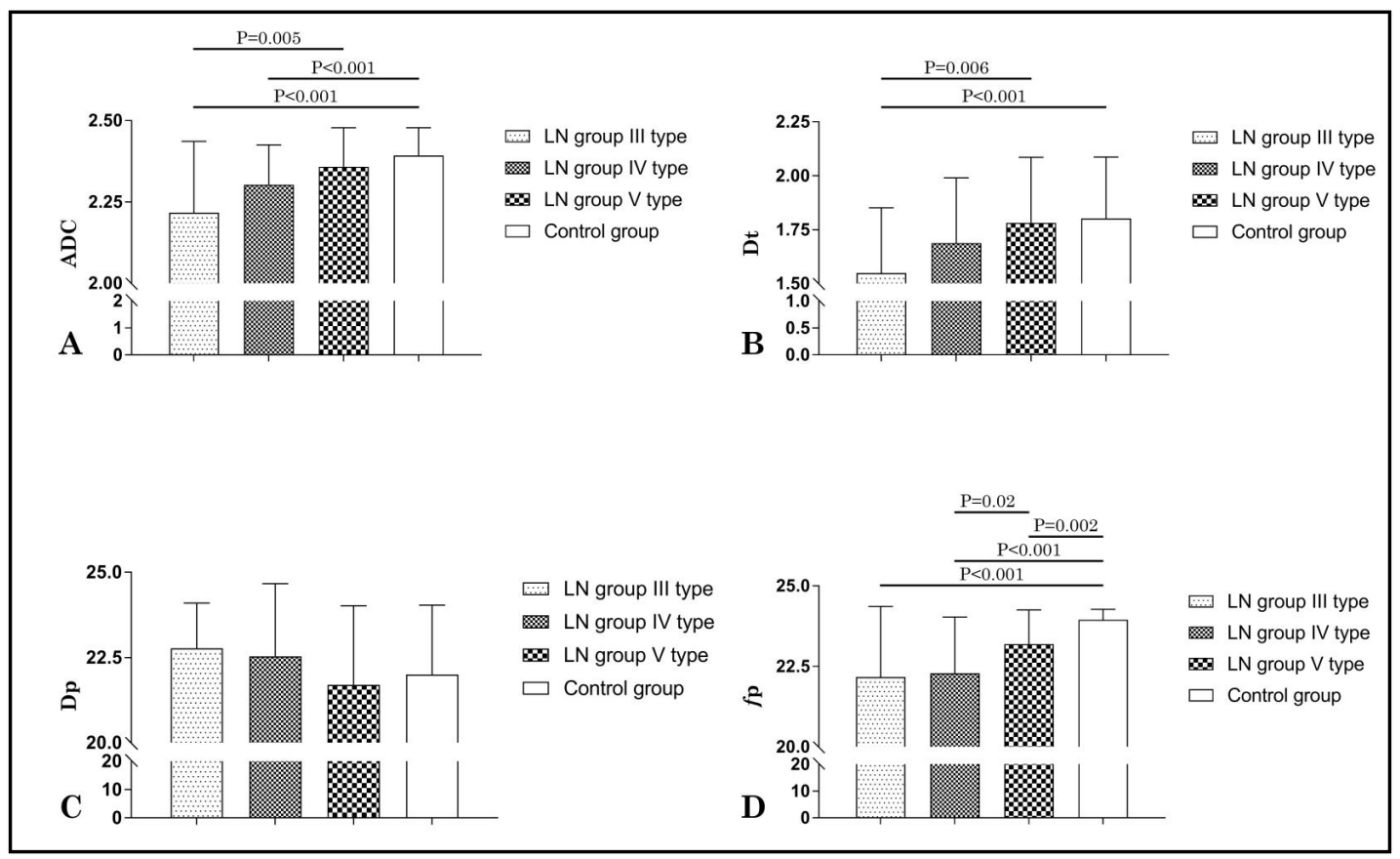

Fig. 2. Comparison of renal cortical DWI indices among three subclasseses of lupus nephritis and healthy volunteers. 


\section{Kidney Blood Pressure Research}

Table 4. Comparison of DWI functions in the renal medulla between lupus nephritis subgroups and healthy volunteers. Note: ADC: appearance diffusion coefficient; $\mathrm{D}_{\mathrm{t}}$ : true diffusion coefficient; $\mathrm{D}_{\mathrm{p}}$ : pseudo-diffusion coefficient; and $\mathrm{f}_{\mathrm{p}}$ : perfusion fraction. Data are shown as mean $\pm \mathrm{SD}$

\begin{tabular}{lcccc}
\hline DWI functions & Lupus nephritis III class $(\mathrm{N}=5)$ & Lupus nephritis IV class $(\mathrm{N}=11)$ & Lupus nephritis V class $(\mathrm{N}=4)$ & Healthy volunteers $(\mathrm{N}=11)$ \\
\hline $\mathrm{ADC}$ & $2.212 \pm 0.176$ & $2.276 \pm 0.136$ & $2.302 \pm 0.172$ & $2.358 \pm 0.067$ \\
$\mathrm{D}_{\mathrm{t}}$ & $1.422 \pm 0.224$ & $1.660 \pm 0.310$ & $1.668 \pm 0.423$ & $<0.001$ \\
$\mathrm{D}_{\mathrm{p}}$ & $23.179 \pm 1.136$ & $23.237 \pm 1.157$ & $22.761 \pm 1.835$ & $1.735 \pm 0.272$ \\
$\mathrm{f}_{\mathrm{p}}$ & $22.118 \pm 1.761$ & $22.712 \pm 1.088$ & $22.575 \pm 0.939$ & $22.528 \pm 1.633$ \\
\hline
\end{tabular}

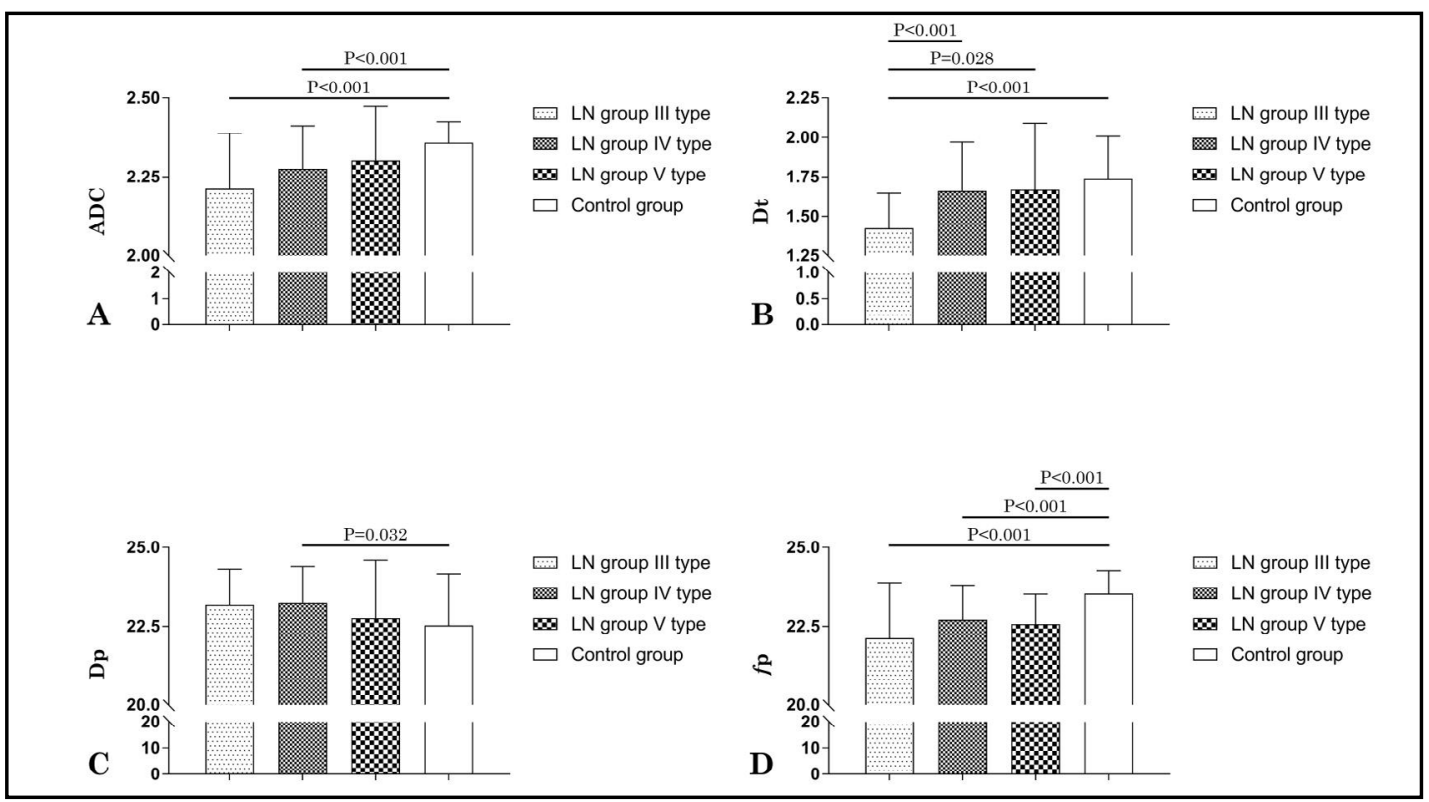

Fig. 3. Comparison of renal medullary DWI indices among three subclasses of lupus nephritis and healthy volunteers.

Fig. 4. Multiple correspondence analysis of ADC and renal pathological par a m eter s in 20 lupus $\mathrm{n}$ e $\mathrm{ph} \mathrm{r}$ i t i s patients.

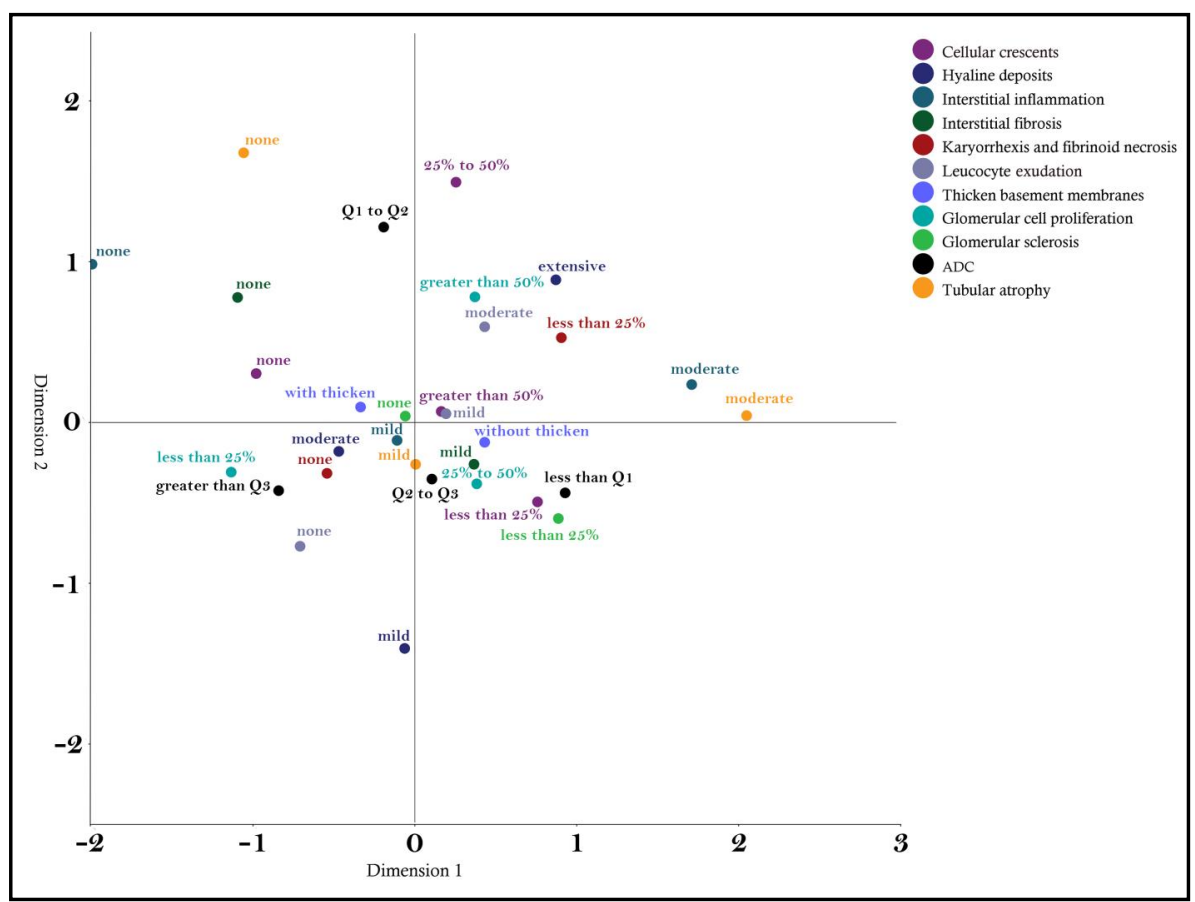




\section{Kidney Bloód Pressure Research}

In the MCA figure showing the relationship between $\mathrm{D}_{\mathrm{p}}$ and renal pathological indices, the higher $\mathrm{D}_{\mathrm{p}}$ values and several pathological injures, such as cellular crescents, glomerular cell proliferation, interstitial fibrosis, hyaline deposits, and tubular atrophy, were scattered in the same quadrant; details are provided in Fig. 6. Similar results were also found in the MCA figure showing the relationship between $\mathrm{f}_{\mathrm{p}}$ values and renal pathological indices. These results demonstrate the close correlation between renal pathological injures and fluid perfusion; details are provided in Fig. 7.

Fig. 5. Multiple correspondence analysis of $\mathrm{D}_{\mathrm{t}}$ and renal pathological parameters in 20 lupus nephritis patients.

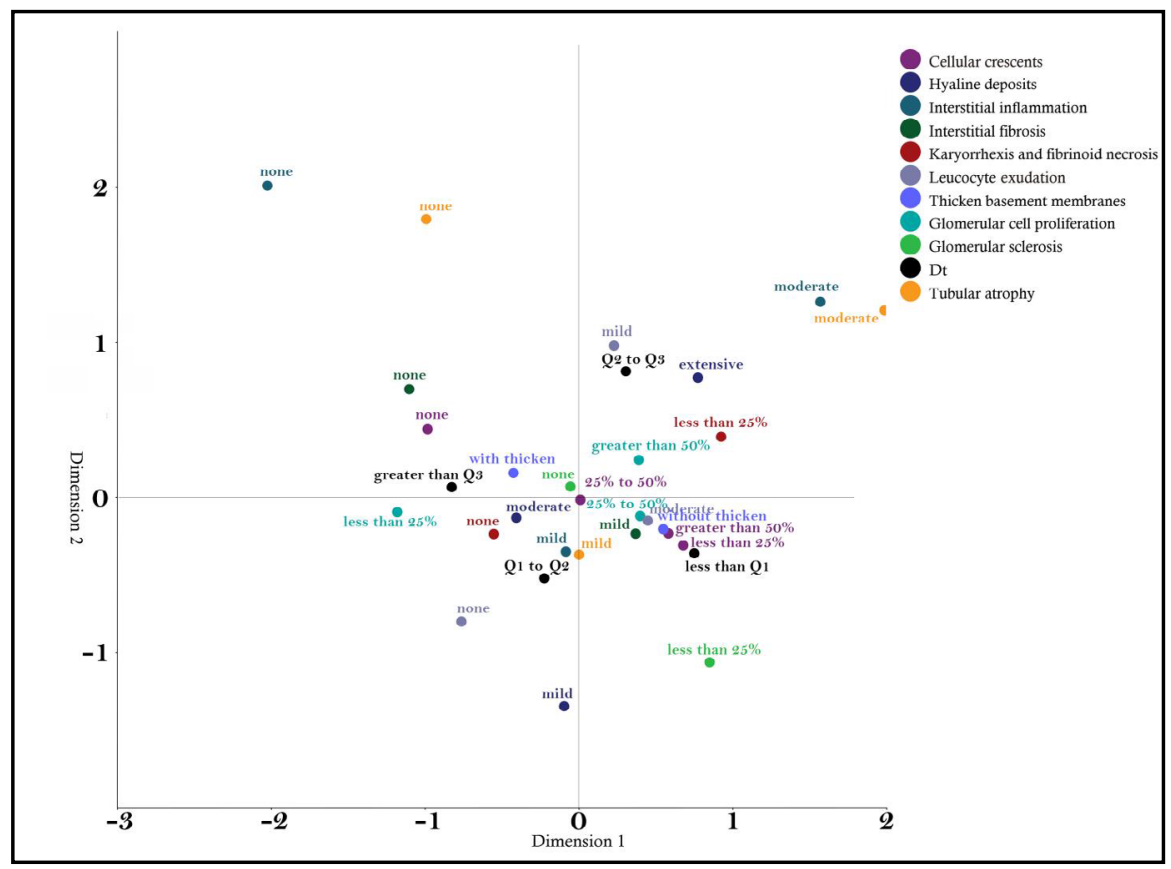

Fig. 6. Multiple correspondence analysis of $\mathrm{D}_{\mathrm{p}}$ and renal pathological parameters in 20 lupus nephritis patients.

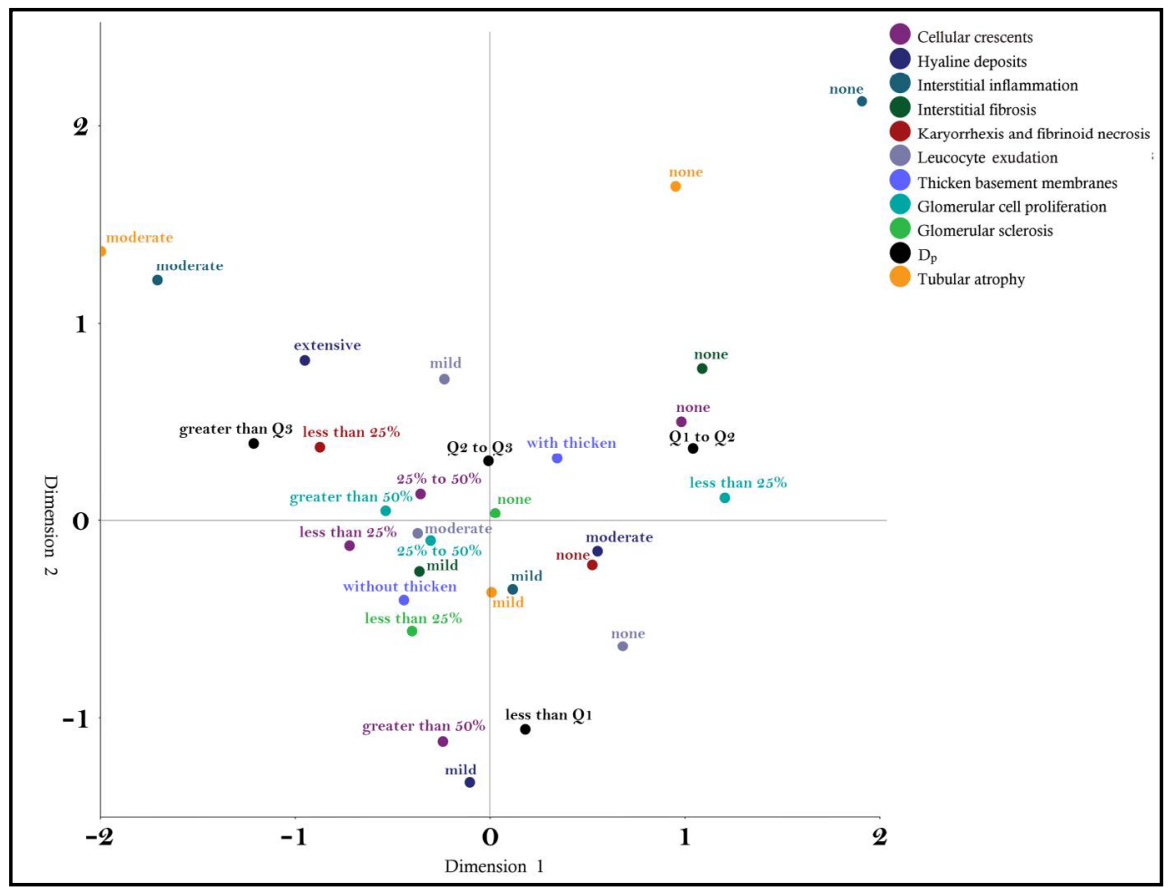




\section{Kidney Blood Pressure Research}

Fig. 7. Multiple correspondence analysis of $\mathrm{f}_{\mathrm{p}}$ and renal pathological parameters in 20 lupus nephritis patients.

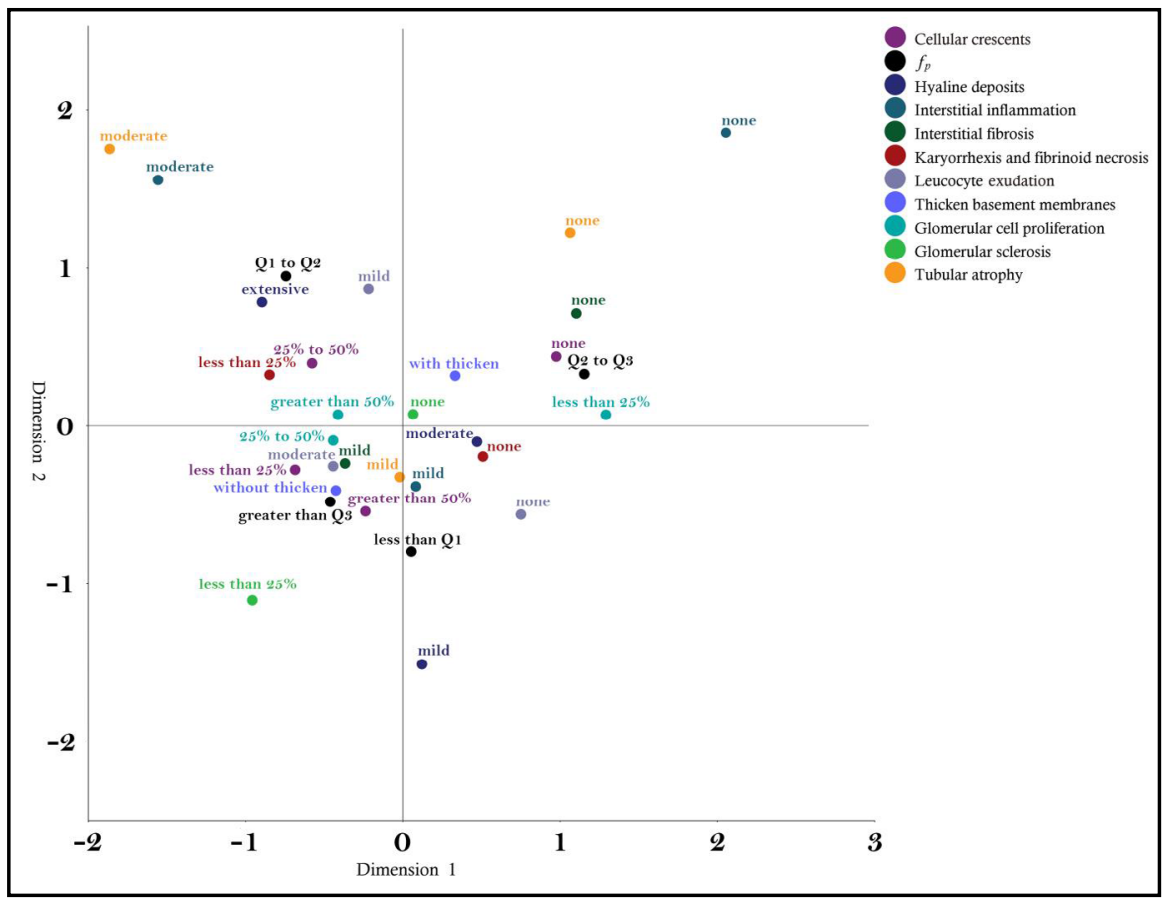

\section{Discussion}

The current study investigated the discrepancy between diffusion and tissue perfusion in patients with LN and healthy volunteers. The DWI-MRI results implied that decreased diffusion and incremental fluid perfusion co-existed in renal tissues in patients with LN. We speculated that these abnormal manifestations of intra-renal fluid movement might correlate with pathophysiological changes in LN. Previous studies have shown that multiple pathological injuries are found in both the glomerular and tubule-interstitial areas. The injuries included the proliferation of endothelial and mesangial cells, proliferation of parietal epithelial cells, crescent formation, tubular atrophy, and interstitial fibrosis [19]. These pathological injuries may weaken the capacity for the free diffusion of fluid, which has been observed by DWI-MRI. For example, Li et al. compared renal ADC values between $65 \mathrm{LN}$ patients and 16 healthy volunteers and they found that the mean ADC values of the kidneys in LN patients were significantly lower than in the healthy volunteers regardless of both the renal cortex and renal medulla area [13]. Although the precise mechanism behind the decline of $A D C$ and $D_{t}$ has not been determined, it may be due to higher cell density. Increased tissue cell density can lead to fluid redistribution in the tissue microenvironment. For example, Chin et al. found that high cell density decreased the extracellular water fraction and increased the intracellular water fraction, resulting in a lower ADC [20]. In contrast, our study results showed an increase in perfusion in both the renal cortex and renal medulla. This may be due to renal pathological injuries that give rise to neovascularization in patients with LN. In a study by Frieri et al., vascular endothelial growth factor (VEGF) expression in the renal tissues of eight LN patients was compared with a healthy control group. Their results showed a significant increase in VEGF expression in the LN group [21]. Similarly, Ding et al. measured VEGF levels in $41 \mathrm{LN}$ patients and found higher blood and urinary VEGF levels in the LN group [22]. Therefore, increased VEGF levels may promote the microvascular proliferation and increased water molecular perfusion detected by DWI-MRI.

In the current study, we also compared the DWI parameters of the renal cortex and medulla in both the LN and healthy volunteer groups. In the healthy volunteer group, there was a difference in two of the DWI parameters (ADC and $f_{p}$ ) between the cortex and 


\section{Kidney Blood Pressure Research}

Kidney Blood Press Res 2018;43:847-859

\begin{tabular}{l|l}
\hline DOI: $10.1159 / 000490333$ & (C) 2018 The Author(s). Published by S. Karger AG, Basel
\end{tabular}

Published online: 5 June, 2018

www.karger.com/kb

Zheng et al.: DWI MRI in Lupus Nephritis

medulla. However, the DWI parameters, $\mathrm{D}_{t}$ and $\mathrm{D}_{\mathrm{p}}$, which represent molecular diffusion and perfusion, respectively, were not significantly different between the renal cortex and the medulla. Therefore, we speculate that diffusion and perfusion in the renal cortex and medulla is similar under normal physiological conditions in a healthy population. To maintain an optimal glomerular filtration rate and cortical-medullary solute gradient, most blood is directed towards the renal cortex, where approximately $10 \%$ of the renal blood supply is dedicated to medullary afflux [23]. Since the PF value represents the proportion of the DWI-MRI signal that is perfusion, the higher PF value in the cortex may reveal this renal physiological characteristic in our current study. One interesting result of the current study was the contradictory data showing differential values of ADC and Dt between the cortex and medulla. Although these two DWI parameters are thought to be indices of diffusion, there were still slight distinctions between the two parameters. In contrast with how the ADC was calculated, $D_{t}$ was calculated using the biexponential formula with consideration of the effect of intravoxel incoherent motion (IVIM) [6]. The IVIM effect might be mistaken as a diffusion effect when using the monoexponential formula, which was utilized to calculate the ADC parameter. In patients from the LN group, a difference in two parameters $\left(D_{t}\right.$ and $\left.D_{p}\right)$ between the renal cortex and medulla were observed. Compared with the same index in the healthy volunteer group, the $D_{t}$ values were lower in both the cortical and medullary tissues. Since $D_{t}$ values in the medullary area declined significantly, the cortical-medullary statistical distinction of this index was detected by DWI. We presume that diffusion in the renal medulla was affected by various pathological changes in patients with LN. Unfortunately, there was not enough renal pathological evidence to test this theory because there is a high risk of bleeding during a medullary tissue biopsy. However, based on renal cortical-medullary tissue and cellar structure and physiological functional discrepancies, we could detect the more serious renal parenchymal fibrosis located in the medullary area. Previous studies have shown a correlation between decreased ADC and the magnitude of fibrosis [24, 25]. However, other studies have shown the opposite effect with $\mathrm{D}_{\mathrm{p}}$. The fluid perfusion capacity in the microenvironment of patients with LN was significantly reinforced, particularly in the renal medulla. We hypothesized that the enhanced fluid perfusion effect in the renal parenchyma could be a compensatory pathophysiological mechanism by which the tissue may compensate for the diminishing diffusion effect in the tissue microenvironment. Although an explanation for the higher perfusion effect detected in the renal medulla is unknown, previous studies may provide a potential mechanism. For example, studies have shown that intrarenal nitric oxide (NO) levels increase in patients with LN compared with healthy controls. NO is produced by a family of NO synthases (NOS), of which three major isoforms exist, namely, neuronal (nNOS), inducible (iNOS), and endothelial (eNOS) NOS, which have been detected in the renal parenchyma [26, 27]. Furthermore, nNOS is predominantly present in the macula densa; iNOS is located in the medullary thick ascending limb and collecting ducts; and eNOS is scattered in the glomerular capillaries, intra-renal arteries and arterioles, vasa recta, proximal tubules, and thick ascending limbs $[28,29]$. Previous studies have shown higher NOS activity in the medulla compared to the cortex [30].

$D_{t}$ and $D_{p}$ represented the water molecule free diffusion capability and microenvironment perfusion capability, respectively. We speculated that there was a similar renal cellular and tissue physiological condition in the both cortex and medulla in healthy volunteers. However, significant differences of these two DWI parameters were detected between the cortex and medulla in the LN group. These results might indicate that LN pathophysiological injuries have an impact on different effects in the renal cortex and renal medulla. Although some previous studies showed the close correlation between ADC value and eGFR, we did not think that these DWI parameters were used to measure the glomerular function. The DWI-MRI technique was used to detect water molecule and fluid movement rather than glomerular blood flow.

We also explored the correlation between the eGFR and DWI parameters. Unfortunately, no substantial correlative findings were detected on the basis of our research data. 


\section{Kidney Blood Pressure Research}

Kidney Blood Press Res 2018;43:847-859

\begin{tabular}{l|l}
\hline DOI: $10.1159 / 000490333$ & (C) 2018 The Author(s). Published by S. Karger AG, Basel
\end{tabular}

Published online: 5 June, 2018

www.karger.com/kb

Zheng et al.: DWI MRI in Lupus Nephritis

We speculated several possible reasons might lead to our current results. First, renal pathophysiological injuries of LN were sophisticated. Different pathological patterns or injury degree might impact eGFR in complicated ways. The higher pathological heterogeneity perhaps disturbed the correlation of the DWI parameters and eGFR. Second, the clinical index of eGFR implied the renal eliminating fluid capacity. However, the DWI parameters, such as $D_{t}$ and $D_{p}$, represented water molecule free diffusion capacity and microenvironment fluid perfusion capability. There were still substantial differences when detecting renal pathophysiological status. Third, our study only included $20 \mathrm{LN}$ patients. We did not exclude the possibility of sample error. Based on these reasons, we did not recommend using these DWI indexes to measure the glomerular function.

The current study also investigated the characteristics of diffusion and perfusion among the different pathological patterns of LN. Surprisingly, we found that the lowest renal diffusion levels were detected in patients with Class III LN instead of Class IV LN. It is well recognized that the pathological injuries in Class IV are more serious than in Class III. However, our results did not show a difference in diffusion between Class III and Class IV in both the cortex and medulla. Moreover, we found lower diffusion in the Class III group instead of the Class IV group when compared to the Class V and healthy volunteer groups. These results suggest that the relationship between renal pathological changes is complex, as is their impact on diffusion.

In addition, we assessed the difference in perfusion levels in three pattern LN groups and the healthy volunteer group. Interestingly, two perfusion indices, $\mathrm{D}_{\mathrm{p}}$ and $\mathrm{f}_{\mathrm{p}^{\prime}}$ showed opposite results. We did not find obvious changes in $\mathrm{D}_{\mathrm{p}}$ levels among the different groups, except for the Class IV LN group $\mathrm{D}_{\mathrm{p}}$ values in the medulla. In contrast, the PF index in all three of the pattern LN groups showed lower values when compared with the healthy volunteer group in both the cortical and medullary areas. Since $D_{p}$ denotes perfusion, and $f_{p}$ represents the proportion of tissue perfusion, we hypothesized that the perfusion effect was not significantly enhanced in patients with LN, particularly in the cortical area. However, the proportion of perfusion in the renal tissue microenvironment was significantly decreased in comparison with healthy volunteers, especially in the Class IV group, which had more serious pathological injuries. We therefore speculated that the $f_{p}$ values may correlate with the extent of tubular atrophy and microvascular thrombosis.

To explore the correlation between changes in diffusion and perfusion and multiple pathological injuries, a multivariate technique (MCA) was used to visualize this relationship within a set of categorical variables. In the MCA plot of $D_{t}$ and pathological injuries, the lowest $\mathrm{D}_{\mathrm{t}}$ (less than Q1) was located in the lower right quadrant. Cellular crescents, glomerular cell proliferation, interstitial fibrosis, and leucocyte exudation in the absence of thickened basement membranes were also distributed in the same area. These results imply that renal cell and extracellular matrix proliferation, inflammatory cell infiltration, and interstitial fibrosis may be major factors that impact water diffusion. In the MCA plot of $D_{p}$ and pathological injuries, the highest $D_{p}$ (greater than Q3) was located in the upper left quadrant. Similar pathological pattern injuries were also scattered in the same quadrant. It appeared that serious proliferative pathological changes may be concomitant with enhanced tissue microenvironment perfusion. Therefore, we hypothesized that this variation is one mechanism of renal compensation.

There were several limitations in the current study. First, the study had a small sample size of $20 \mathrm{LN}$ patients and 11 healthy volunteers. The sample was too small to gain a robust result. Moreover, other pathological classes and subclasses, such as class II, III-C, III-A, IV$\mathrm{G}(\mathrm{C})$, IV-S(A) or VI, were not included in this study. Second, other factors, such as blood pressure and water or liquid intake, which could potentially impact DWI parameters, were not analyzed. Third, although the MCA plots provided a visual correlation between the DWI parameters and pathological injury patterns, the MCA technique is a statistical exploration technique instead of a statistical test, which would provide robust results. Fourth, our current study did not analyze the correlation between volume status and DWI parameters. 


\section{Kidney \\ Blood Pressure Research}

Zheng et al.: DWI MRI in Lupus Nephritis

Several impersonal reasons give rise to the failure to assess the participants' volume status accurately. For example, our hospital provided several static and dynamic volume status techniques. However, these techniques were all invasive and all of participants refused these medial inspections. Noninvasive assessing techniques, such as bioelectrical impedance analysis (BIA) or noninvasive cardiac output monitor (NiCOM), were not available in our study. Therefore, future studies are needed to definitively show the relationship between the DWI parameters and renal pathological indices in patients with LN.

\section{Conclusion}

DWI-MRI is a useful non-invasive technique for detecting renal pathophysiological changes. Pathological injuries in patients with LN may decrease diffusion, while renal cell proliferation and intestinal fibrosis may impact the free movement of fluids in tissue microenvironments. Enhanced perfusion is a potential compensatory mechanism associated with renal pathological injuries. DWI parameters may be linked with multiple pathological indices; however, the relationship is complex.

\section{Acknowledgements}

We would like to thank LetPub (www.LetPub.com) for providing linguistic assistance during the preparation of this manuscript.

\section{Disclosure Statement}

The authors declare that they have no competing interests.

\section{References}

1 Rahman A, Isenberg DA: Systemic lupus erythematosus. N Engl J Med 2008;358:929-939.

2 Danila MI, Pons-Estel GJ, Zhang J, Vila LM, Reveille JD, Alarcon GS: Renal damage is the most important predictor of mortality within the damage index: data from LUMINA LXIV, a multiethnic US cohort. Rheumatology (Oxford) 2009;48:542-545.

3 Pan Q Li Y, Ye L, Deng Z, Li L, Feng Y, Liu W, Liu H: Geographical distribution, a risk factor for the incidence of lupus nephritis in China. BMC Nephrol 2014;15:67.

4 Zhang JL, Rusinek H, Chandarana H, Lee VS: Functional MRI of the kidneys. J Magn Reson Imaging 2013;37:282-293.

5 Dyvorne HA, Galea N, Nevers T, Fiel MI, Carpenter D, Wong E, Orton M, de Oliveira A, Feiweier T, Vachon ML, Babb JS, Taouli B: Diffusion-weighted imaging of the liver with multiple b values: effect of diffusion gradient polarity and breathing acquisition on image quality and intravoxel incoherent motion parameters--a pilot study. Radiology 2013;266:920-929.

6 Le Bihan D, Breton E, Lallemand D, Aubin ML, Vignaud J, Laval-Jeantet M: Separation of diffusion and perfusion in intravoxel incoherent motion MR imaging. Radiology 1988;168:497-505.

-7 Ichikawa S, Motosugi U, Ichikawa T, Sano K, Morisaka H, Araki T: Intravoxel incoherent motion imaging of the kidney: alterations in diffusion and perfusion in patients with renal dysfunction. Magn Reson Imaging 2013;31:414-417.

-8 Thoeny HC, De Keyzer F, Oyen RH, Peeters RR: Diffusion-weighted MR imaging of kidneys in healthy volunteers and patients with parenchymal diseases: initial experience. Radiology 2005;235:911-917.

-9 Emre T, Kilickesmez O, Buker A, Inal BB, Dogan H, Ecder T: Renal function and diffusion-weighted imaging: a new method to diagnose kidney failure before losing half function. Radiol Med 2016;121:163-172. 


\section{Kidney \\ Blood Pressure Research}

10 Ren T, Wen CL, Chen LH, Xie SS, Cheng Y, Fu YX, Oesingmann N, de Oliveira A, Zuo PL, Yin JZ, Xia S, Shen W: Evaluation of renal allografts function early after transplantation using intravoxel incoherent motion and arterial spin labeling MRI. Magn Reson Imaging 2016;34:908-914.

11 Li Q Li J, Zhang L, Chen Y, Zhang M, Yan F: Diffusion-weighted imaging in assessing renal pathology of chronic kidney disease: A preliminary clinical study. Eur J Radiol 2014;83:756-762.

12 Rapacchi S, Smith RX, Wang Y, Yan L, Sigalov V, Krasileva KE, Karpouzas G, Plotnik A, Sayre J, Hernandez E, Verma A, Burkly L, Wisniacki N, Torrington J, He X, Hu P, Chiao PC, Wang DJJ: Towards the identification of multi-parametric quantitative MRI biomarkers in lupus nephritis. Magn Reson Imaging 2015;33:10661074.

-13 Li X, Xu X, Zhang Q, Ren H, Zhang W, Liu Y, Yan F, Chen N: Diffusion weighted imaging and blood oxygen level-dependent MR imaging of kidneys in patients with lupus nephritis. J Transl Med 2014;12:295.

14 Petri M, Orbai AM, Alarcon GS, Gordon C, Merrill JT, Fortin PR, Bruce IN, Isenberg D, Wallace DJ, Nived O, Sturfelt G, Ramsey-Goldman R, Bae SC, Hanly JG, Sanchez-Guerrero J, Clarke A, Aranow C, Manzi S, Urowitz M, Gladman D, et al.: Derivation and validation of the Systemic Lupus International Collaborating Clinics classification criteria for systemic lupus erythematosus. Arthritis Rheum 2012;64:2677-2686.

15 Ibanez D, Urowitz MB, Gladman DD: Summarizing disease features over time: I. Adjusted mean SLEDAI derivation and application to an index of disease activity in lupus. J Rheumatol 2003;30:1977-1982.

16 Levey AS, Stevens LA, Schmid CH, Zhang YL, Castro AF, 3rd, Feldman HI, Kusek JW, Eggers P, Van Lente F, Greene T, Coresh J, Ckd EPI: A new equation to estimate glomerular filtration rate. Ann Intern Med 2009;150:604-612.

17 Weening JJ, D’Agati VD, Schwartz MM, Seshan SV, Alpers CE, Appel GB, Balow JE, Bruijn JA, Cook T, Ferrario F, Fogo AB, Ginzler EM, Hebert L, Hill G, Hill P, Jennette JC, Kong NC, Lesavre P, Lockshin M, Looi LM, et al.: The classification of glomerulonephritis in systemic lupus erythematosus revisited. Kidney Int 2004;65:521-530.

18 Austin HA 3rd, Muenz LR, Joyce KM, Antonovych TT, Balow JE: Diffuse proliferative lupus nephritis: identification of specific pathologic features affecting renal outcome. Kidney Int 1984;25:689-695.

19 Lech M, Anders HJ: The pathogenesis of lupus nephritis. J Am Soc Nephrol 2013;24:1357-1366.

20 Chin CL, Wehrli FW, Hwang SN, Takahashi M, Hackney DB: Biexponential diffusion attenuation in the rat spinal cord: computer simulations based on anatomic images of axonal architecture. Magn Reson Med 2002;47:455-460.

21 Frieri M, Samih MA, Dzhindzhikhashvili M, Liu H, Balsam L, Rubinstein S: Toll-like receptor 9 and vascular endothelial growth factor levels in human kidneys from lupus nephritis patients. J Nephrol 2012;25:10411046.

22 Ding Y, Liao W, Yi Z, Xiang W, He X: Association of miRNA-145 expression in vascular smooth muscle cells with vascular damages in patients with lupus nephritis. Int J Clin Exp Pathol 2015;8:12646-12656.

23 Pallone TL, Robertson CR, Jamison RL: Renal medullary microcirculation. Physiol Rev 1990;70:885-920.

24 Zhao J, Wang ZJ, Liu M, Zhu J, Zhang X, Zhang T, Li S, Li Y: Assessment of renal fibrosis in chronic kidney disease using diffusion-weighted MRI. Clin Radiol 2014;69:1117-1122.

-25 Inoue T, Kozawa E, Okada H, Inukai K, Watanabe S, Kikuta T, Watanabe Y, Takenaka T, Katayama S, Tanaka J, Suzuki H: Noninvasive Evaluation of Kidney Hypoxia and Fibrosis Using Magnetic Resonance Imaging. J Am Soc Nephrol 2011;22:1429-1434.

26 Kone BC: Nitric oxide in renal health and disease. Am J Kidney Dis 1997;30:311-333.

-27 Kone BC, Baylis C: Biosynthesis and homeostatic roles of nitric oxide in the normal kidney. Am J Physiol 1997;272:F561-578.

28 Ahn KY, Mohaupt MG, Madsen KM, Kone BC: In situ hybridization localization of mRNA encoding inducible nitric oxide synthase in rat kidney. Am J Physiol 1994;267:F748-757.

29 Bachmann S, Bosse HM, Mundel P: Topography of nitric oxide synthesis by localizing constitutive NO synthases in mammalian kidney. Am J Physiol 1995;268:F885-F898.

30 Wu F, Park F, Cowley AW, Jr., Mattson DL: Quantification of nitric oxide synthase activity in microdissected segments of the rat kidney. Am J Physiol 1999;276:F874-881. 